\title{
Obituary of Theodore L. Sourkes, PhD, FRSC, OC
}

With the death of Theodore L. Sourkes on Jan. 17, 2015, at age 95, the CCNP, Canada and the international research community lost one of the pioneers of a research discipline: the study of the biochemistry of the brain in relation to mental and neurological disorders.

Ted was born in Montréal, Que., the city where he spent much of his life, in 1919. He obtained a Bachelor of Science from McGill University in 1939. Unable to join the Canadian army for health reasons, he worked at jobs that served the war effort: as a chemist in an engineering company and as a biochemist in a pharmaceutical company. In 1945 he joined the Department of Nutrition at McGill University and obtained his Master of Science working with E.W. Crampton, Canada's most distinguished nutritional scientist. In 1946 he moved to Cornell University to work with the Nobel Prize winner James B. Sumner and obtained his doctorate in 1948. After a brief period as an assistant professor in pharmacology at Georgetown University in Washington, DC, Ted joined the Merck Institute for Therapeutic Research in Rahway, New Jersey. His research there contributed to the development of $\alpha$-methyldopa as an antihypertensive drug, and it remains on the World Health Organization List of Essential Medicines. After 3 years at Merck, he moved back to Montréal in 1953 to take an appointment in the Department of Psychiatry at McGill University, where he remained for the rest of his life.

Ted's broad experience before becoming an independent investigator enabled him to make many novel contributions. For example, his experience with $\alpha$-methyldopa stimulated an interest in methylated aromatic amino acids. One of his first highly cited papers demonstrated that $\alpha$-methyltryptophan induced the catabolism of tryptophan through the kynurenine pathway, an early result that helped in the genesis of the current hot topic of how peripheral metabolism of tryptophan can influence both serotonin metabolism and psychoactive kynurenine pathway metabolites in the brain. More than 3 decades later, Ted suggested that $\alpha$-methyltryptophan could be used as a tracer to measure human brain serotonin synthesis with positron emission tomography because of its metabolism to $\alpha$-methyl-serotonin. The method that was developed is still being used.

Ted was always concerned with rigour in research studies. For example, at McGill he developed and set up what were, given the equipment available at the time, sophisticated analytical techniques to measure biogenic amines and their metabolites. His laboratory was one of only a few in the world at that time that could measure them accurately and reliably. In the early 1970s he published a series of papers that helped define the advantages and limitations of measuring biogenic amine metabolites in cerebrospinal fluid as an indication of the metabolism of the parent amines in the brain.

While Ted remained interested in tryptophan and serotonin throughout his career, his primary interest was the catecholamines, and he carried out studies in both experimental animals and humans. His discovery that patients with Parkinson disease excrete low levels of dopamine was one of the findings that led Ted to propose DOPA as a treatment for Parkinson disease. Two studies reporting improvement of symptoms in patients with Parkinson disease treated with DOPA were conducted at about the same time with Ted in Montréal and with Oleh Hornykiewicz in Vienna. Subsequently, Ted published on the existence of the nigrotriatal pathway at about the same times as a less detailed paper by Arvid Carlsson.

Ted not only published research on a range of topics much too broad to discuss here, but also published influential reviews. Already in the late 1950s he was publishing reviews on topics such as biochemical theories of psychosis and biochemical research in psychiatry. In 1962 he published a 400-page book, The Biochemistry of Mental Disease, which was one of the first books covering that topic and possibly the most comprehensive at that time.

Ted was always interested in the history of science, and in 1967 he published the book Nobel Prize Winners in Medicine and Physiology. For 2 decades starting in the 1990s, after he retired, he published many articles on the history of science, for which he received awards from the International Society for the History of the Neurosciences.

Ted trained 26 graduate students, 22 postdoctoral fellows with a Doctorate in Medicine and 13 with a Doctorate in Philosophy. Ted thought carefully about the topics for trainees to work on. He gave his trainees a lot of freedom. The default position of his office door was open when he was at work, and he was always ready to discuss ideas trainees might come up with and to fund the studies if appropriate. He was generous in funding trainees to attend local and international meetings. As might be expected in these circumstances many of his former trainees went on to have successful careers as independent investigators.

When asked, Ted was always available to give advice to trainees and to other researchers in the growing field of biological psychiatry. However, he was also influential through example. While currently there is a lot of discussion of balancing life at work and at home, when Ted started out in his career the attitude that work always came first was much more dominant. However, anyone who worked with 
Ted soon became aware of the importance of family in his life and the fact that he and his wife Shena adored each other (and undoubtedly remained that way through 72 years of marriage). Those who saw Ted with his daughters Barbara and Myra could see that he doted on them and he would mention how proud he was of the fact that Barbara became a clinical psychologist and Myra a neurologist.
Ted received many awards, including the first Heinz Lehmann Award from the CCNP, the CCNP medal and the Wilder Penfield Prix du Québec. He was a Fellow of the Royal Society of Canada and an Officer of the Order of Canada. He was the right person at the right time. His research contributed in a significant way to the foundation of an important and flourishing research topic.

Written by Simon Young, PhD, Department of Psychiatry, McGill University, Montréal, Que., Canada; Maryka Quik, PhD, Neurodegenerative Diseases Program, Center for Health Sciences, SRI International, Menlo Park, Calif., USA; Guillermina Almazan PhD, Department of Pharmacology, McGill University, Montréal, Que., Canada; and Marc Ekker, PhD, Centre for Advanced Research in Environmental Genomics, Department of Biology, University of Ottawa, Ottawa, Ont., Canada. Dr. Young was a postdoctoral fellow with Ted from 1971-75, and Drs. Quik (1972-76), Almazan (1978-82) and Ekker (1981-85) were graduate students with Ted.

\section{Canadian College of Neuropsychopharmacology 2015 award winners}

\section{Heinz Lehmann Award}

Dr. Derek van der Kooy is the recipient of the 2015 CCNP Heinz Lehmann Award. Dr. van der Kooy is a Professor in the Departments of Molecular Genetics, Medical Biophysics and the Institute of Science in Toronto, Ont. Dr. van der Kooy is also a founding fellow and committee member of the Ontario Institutes for Regenerative Medicine and head of the Pancreas Program for Regenerative Medicine at the McEwen Centre for Regenerative Medicine. This award is designed to recognize outstanding research achievements by Canadian scientists in the field of neuropsychopharmacology, and this year the award is for clinical/translational research. The award, donated by Pfizer Canada Inc., consists of a \$2000 honorarium and a suitably engraved plaque. Congratulations to Dr. van der Kooy!

\section{Innovations in Neuropsychopharmacology Award}

Dr. Marco Leyton is the recipient of the 2015 CCNP Innovations in Neuropsychopharmacology Award. Dr. Leyton is a Professor and William Dawson Chair in McGill University's Departments of Psychiatry, Psychology and Neurology \& Neurosurgery in Montréal, Que. Dr. Leyton is also a past President of the CCNP and a founding member of the Scientific Advisory Committee to the Canadian Centre on Substance Abuse. This award is designed to recognize outstanding and innovative research in the basic or clinical fields of neuropsychopharmacology, and this year the award is for clinical/translational research. The award, donated by Pfizer Canada Inc., consists of a $\$ 2000$ honorarium and a suitably engraved plaque. Congratulations to Dr. Leyton!

\section{Young Investigator Award}

Dr. Sherif Karama is the recipient of the 2015 CCNP Young Investigator Award. Dr. Karama is an assistant professor in the Department of Psychiatry at McGill University in Montréal, Que., and an independent scientist since finishing his postdoctoral fellowship in structural neuroimaging of higher cognitive functions in June 2012. This award is designed to recognize outstanding contributions in the field of research in neuropsychopharmacology by an individual young basic scientist or clinical investigator in Canada, and this year the award is for basic/translational research. The award, donated by Pfizer Canada Inc., consists of a $\$ 2000$ honorarium and a suitably engraved plaque. Congratulations to Dr. Karama!

\section{CCNP Medal}

Dr. Ashok Malla is the recipient of the 2015 CCNP Medal. Dr. Malla is a Professor of Psychiatry and a Tier 1 Canada Research Chair in Early Psychosis at McGill University in Montréal, Que. Dr. Malla also holds a cross-appointment in the Department of Epidemiology and Biostatistics. This award, sponsored by the CCNP, consists of a bronze medal engraved with the name of the recipient. Congratulations to Dr. Malla!

These awards will be conferred at the CCNP 38th Annual Meeting in Ottawa, Ont., June 9-12, 2015. This year's theme is "Discovery and Translational Research in Major Psychiatric Disorders." The program this year is outstanding, with several keynote speakers, including the plenary speaker Dr. Michel Hamon, CCNP Awardees and University of Ottawa Brain and Mind speaker Dr. Eric Nestler. We have also selected 9 excellent symposia with Canadian and international speakers, including a Canada-India symposium. View the complete program at conp.ca. 